\title{
Atividade da enzima redutase do nitrato e teores de prolina livre em raízes de cana-de-açúcar sob os estresses hídrico e ácido no solo
}

\author{
Nitrate reductase enzyme activity and free proline contents in \\ sugarcane roots under water and acid stress in soil
}

\author{
Andressa Freitas de Lima Rhein ${ }^{1}$; Durvalina Maria Mathias dos Santos²; \\ Samira Domingues Carlin ${ }^{3 *}$
}

\begin{abstract}
Resumo
O objetivo deste trabalho foi avaliar indicadores fisiológicos da associação entre deficiência hídrica e acidez do solo, por meio da determinação da atividade da enzima redutase do nitrato, dos teores de prolina livre e do crescimento inicial do sistema radicular de plantas jovens da cultivar IAC91-5155 de cana-de-açúcar. Aos 30 dias, as mudas, originadas da brotação de uma gema, foram transferidas para vasos de plástico de $12 \mathrm{dm}^{3}$ contendo Latossolo Vermelho distrófico álico e submetidas à associação de três tratamentos de disponibilidade hídrica: sem estresse (70\%), estresse moderado (55\%) e estresse severo (40\%), de acordo com a capacidade de campo, e três níveis de acidez no solo: sem estresse $(55 \%)$, estresse moderado (33\%) e estresse severo (23\%), considerando-se o índice de saturação por bases. O delineamento experimental utilizado foi em blocos casualizados, em esquema fatorial $3 \times 3$, com quatro repetições. Aos 60 dias sob associação dos estresses foram determinados a atividade da enzima redutase do nitrato, os teores de prolina livre e o crescimento inicial do sistema radicular de plantas jovens de cana-de-açúcar. A atividade da enzima redutase do nitrato é indicadora fisiológica do efeito da associação do estresse hídrico e da acidez em condições moderadas no solo, enquanto, a prolina livre é indicadora desses estresses em condições severas. A intensificação da deficiência hídrica reduz o crescimento das raízes de cana-de-açúcar.

Palavras-chave: Estresses abióticos, nitrogênio, osmoprotetor, sistema radicular, Saccharum spp.
\end{abstract}

\begin{abstract}
The aim of this work was evaluate the physiological indicators of association between water deficiency and soil acidity, by determining the nitrate reductase activity, the levels of free proline and initial growth of the root system of seedlings of sugarcane cv. IAC91-5155. After 30 days, the seedlings were transferred to plastic pots with $12 \mathrm{dm} 3$ of dystrophic alic Red Latosol (Oxisol) and submitted to association of three treatments of water availability: no stress $(70 \%)$, moderate stress $(55 \%)$ and severe stress $(40 \%)$, in according with field capacity and three acidity treatments: no stress $(55 \%)$, moderate stress $(33 \%)$ and severe stress (23\%), considering the base saturation. The experimental design was that of random blocks under factorial scheme of $3 \times 3$, with four replicates. After 60 days under the stress association, the levels of free proline, the nitrate reductase activity and the growth of the sugarcane roots system were evaluated in seedlings of sugarcane. The nitrate reductase enzyme activity can be considered a physiological indicator
\end{abstract}

${ }^{1}$ Eng $^{\mathrm{o}}$ Agr $^{\circ}$, Doutoranda em Agricultura, Universidade Estadual Paulista, UNESP. Faculdade de Ciências Agronômicas, Campus de Botucatu, SP. E-mail: andressa_rhein@yahoo.com.br

2 Bióloga, Prof ${ }^{a}$. Adjunta da Universidade Estadual Paulista, UNESP. Faculdade de Ciências Agrárias e Veterinárias, Campus de Jaboticabal, SP. E-mail: dumaria@fcav.unesp.br

3 Eng ${ }^{\mathrm{o}}$ Agr $^{\mathrm{o}}$, Pesquisadora Científica da Agência Paulista de Tecnologia dos Agronegócios, APTA Pólo Centro Oeste. E-mail: sdcarlin@apta.sp.gov.br

*Autor para correspondência

Recebido para publicação 17/04/2010 Aprovado em 02/06/2011 
of the effect of the association of acid and water stress in moderate conditions in soil, while the free proline can be considered physiological indicator to both stress in severe conditions. Water deficiency increasing reduced growth of sugarcane roots.

Key words: Abiotics stress, nitrogen, osmoprotector, root system, Saccharum spp.

\section{Introdução}

A cana-de-açúcar, cultivada no Brasil desde o século XVI, é uma das principais plantas cultivadas no país (AGRIANUAL, 2008). Desde 2006, representa um dos grandes mercados agrícolas brasileiros, com previsão de aumento de $40 \%$ na área plantada e da ordem de $100 \%$ na produção, nos próximos 10 anos (CASARIN; VILLA NOVA; FORLI, 2006). Para tanto, a canade-açúcar não pode estar sob efeito direto dos estresses ambientais, os quais promovem menor desempenho da cultura no campo (CARLIN; SANTOS, 2009).

As respostas dos vegetais sob efeito de um único estresse não podem ser diretamente comparadas às condições de ocorrência simultânea de estresses abióticos que retratam mais fielmente a realidade dos ambientes agrícolas atuais. De modo geral, os estresses ambientais causam sérios prejuízos às plantas e a interação destes potencializa os efeitos deletérios nos vegetais, reduzindo significativamente a produtividade das culturas (SHULAEV et al., 2008).

Os estresses ambientais de grande ocorrência nos solos como a disponibilidade hídrica e a toxicidade por alumínio $\left(\mathrm{Al}^{+3}\right)$ influenciam a produção das culturas durante o estádio vegetativo. No mundo, dos 3,3 bilhões de hectares considerados aptos para a agricultura, em aproximadamente $28 \%$ dos solos cultiváveis pode ocorrer déficit hídrico. Ainda, estima-se que $66 \%$ dos solos da América do Sul são ácidos, cuja elevada saturação por alumínio é limitante para a produtividade vegetal (DRUMMOND et al., 2001).

A demanda por cultivares tolerantes aos estresses ambientais tem gerado interesse na investigação de mecanismos fisiológicos e bioquímicos que possam ser utilizados como indicadores das respostas às condições adversas (KAVI KISHOR et al., 2005), uma vez que estes mecanismos de tolerância das plantas ainda não estão completamente elucidados (GRENNAN, 2006). As características correlacionadas à tolerância à seca são indicadores adequados para a seleção de genótipos tolerantes em programas de melhoramento, a fim de reduzir os efeitos da deficiência hídrica no rendimento das culturas (SILVA et al., 2008).

O ajuste osmótico é uma das principais respostas das plantas ao estresse hídrico e está correlacionado ao grau de tolerância. Neste mecanismo, ocorre a biossíntese e o acúmulo de solutos compatíveis, como o aminoácido prolina, no vacúolo ou no citosol, com função osmoprotetora, o que mantém o equilíbrio hídrico e preserva a integridade celular de proteínas, enzimas e membranas, para a continuidade das atividades vitais, e constitui uma das estratégias adaptativas dos vegetais aos múltiplos efeitos causados pelos estresses (ABDUL JALEEL et al., 2007). Considerado osmólito-chave para o ajuste osmótico de plantas em condições de estresse hídrico, a prolina também atua como soluto compatível em plantas sob o efeito interativo da deficiência hídrica e da toxicidade por alumínio no solo (CARLIN; SANTOS, 2009).

A deficiência hídrica e a acidez do solo também influenciam de forma negativa o metabolismo de compostos nitrogenados, pelo fato de que o nitrogênio é um dos nutrientes mais importantes para o crescimento vegetal (FERREIRA et al., 2002). A enzima redutase do nitrato, principal enzima responsável pela assimilação 
de nitrogênio pelos vegetais, tem a atividade influenciada pela disponibilidade de água e pela acidez do solo (SHARMA; DUBEY, 2005). A estimativa da atividade da enzima redutase do nitrato tem sido utilizada como parâmetro indicativo da resposta fisiológica das plantas aos estresses ambientais (OLIVEIRA et al., 2005). Devido a importância da cana-de-açúcar, o entendimento destes mecanismos de tolerância aos estresses contribuirá significativamente para indicar o melhor manejo visando obter maior produtividade agrícola (KAVI KISHOR et al., 2005).

O objetivo deste trabalho foi avaliar indicadores fisiológicos da associação entre deficiência hídrica e acidez do solo, por meio da determinação da atividade da enzima redutase do nitrato, dos teores de prolina livre e do crescimento inicial do sistema radicular de plantas jovens de cana-de-açúcar.

\section{Material e Métodos}

$\mathrm{O}$ experimento foi conduzido a $615 \mathrm{~m}$ de altitude média, $21^{\circ} 14^{\prime} 05^{\prime} \mathrm{S}$ e $48^{\circ} 17^{\prime} 09^{\prime} \mathrm{W}$, em casa de vegetação localizada na UNESP - Universidade Estadual Paulista, Faculdade de Ciências Agrárias e Veterinárias - FCAV, município de Jaboticabal - SP, no período de agosto a novembro de 2006.

Para o estudo da interação dos estresses hídrico e ácido no solo foi utilizada a cultivar IAC915155 de cana-de-açúcar considerada tolerante à deficiência hídrica no solo (CARLIN; SANTOS, 2009). Cada muda, com 30 dias de idade e sem restrição hídrica, foi obtida a partir de uma gema já em desenvolvimento, proveniente da Unidade de Pesquisa e Desenvolvimento da APTA Pólo Centro-Oeste, Jaú - SP. Após este período, as mudas foram selecionadas e transferidas para vasos de plástico preenchidos com $12 \mathrm{dm}^{3} \mathrm{de}$ Latossolo Vermelho distrófico álico, retirado de área localizada na UNESP, FCAV, Campus de Jaboticabal, na profundidade de 20-40 $\mathrm{cm}$. As análises química e granulométrica do solo estão apresentadas na Tabela 1 .

Tabela 1. Análise química e granulométrica de Latossolo Vermelho distrófico álico.

\begin{tabular}{|c|c|c|c|c|c|c|c|c|c|}
\hline \multirow[b]{2}{*}{$\mathrm{pH} \mathrm{CaCl}{ }_{2}$} & \multicolumn{9}{|c|}{ Análise Química } \\
\hline & M.O. & $\mathrm{P}$ resina & $\mathrm{K}$ & $\mathrm{Ca}$ & $\mathrm{Mg}$ & $\mathrm{H}+\mathrm{Al}$ & SB & $\mathrm{T}$ & $\mathrm{V}$ \\
\hline & $\mathrm{g} \mathrm{dm}^{-3}$ & $\mathrm{mg} \mathrm{dm}^{-3}$ & \multicolumn{6}{|c|}{$\mathrm{mmol}_{\mathrm{c}} \mathrm{dm}^{-3}$} & $\%$ \\
\hline \multirow[t]{2}{*}{4,1} & 14 & 4 & $\overline{1,4}$ & 3 & 2 & 42 & 6,4 & 48,4 & 13 \\
\hline & \multicolumn{9}{|c|}{ Análise Granulométrica } \\
\hline \multirow[t]{3}{*}{ Argila } & \multirow{2}{*}{\multicolumn{2}{|c|}{ Limo }} & & \multicolumn{3}{|c|}{ Areia } & & & \multirow[t]{2}{*}{ Classe Textural } \\
\hline & & & & Fina & & Grossa & & & \\
\hline & \multicolumn{6}{|c|}{ g. $\mathrm{Kg}^{-1}$} & & & \multirow[t]{2}{*}{ Argilosa $^{4}$} \\
\hline 360 & & 50 & & 220 & & 370 & & & \\
\hline
\end{tabular}

M.O.: Matéria Orgânica; SB: Soma de Bases; T: Capacidade de Troca de Cátions; V: Saturação por Bases•

\footnotetext{
4 EMPRESA BRASILEIRA DE PESQUISA AGROPECUÁRIA - EMBRAPA. Centro Nacional de Pesquisa de Solos. Sistema brasileiro de classificação de solos. 2. ed. Rio de Janeiro, 2006. 306 p.
} 
O delineamento experimental utilizado foi o de blocos casualizados, em esquema fatorial $3 \times 3$, com três tratamentos de disponibilidade hídrica $(\mathrm{H})$ e três tratamentos de acidez no solo (A), com quatro repetições. Os dados foram submetidos à análise de variância pelo teste $\mathrm{F}$ utilizando-se do teste de Tukey para a comparação entre médias. A análise da regressão polinomial foi utilizada para o desdobramento dos graus de liberdade dos fatores quantitativos, disponibilidade hídrica e acidez do solo (BANZATTO; KRONKA, 2006).

Os tratamentos de disponibilidade hídrica foram determinados a partir dos valores de microporosidade obtidos pelo método da mesa de tensão com uma coluna de água de $60 \mathrm{~cm}$ de altura, considerando-se a densidade do solo, obtida pela relação entre a massa do solo seco em estufa a $110^{\circ} \mathrm{C}$ durante $24 \mathrm{~h}$, e o volume da amostra de solo indeformada (CLAESSEN, 1997). A microporosidade correspondeu a $100 \%$ da capacidade de campo equivalente a $2,7 \mathrm{~L}$ de água. No entanto, a capacidade de campo do solo foi estabelecida em $70 \%$ da microporosidade, considerada adequada para a maioria das plantas cultivadas. A quantidade de água adicionada foi calculada para cada tratamento de disponibilidade hídrica: sem estresse $\left(\mathrm{H}_{1}: 70 \% ; 1,89 \mathrm{~L}\right)$; estresse moderado $\left(\mathrm{H}_{2}: 55 \% ; 1,49 \mathrm{~L}\right)$ e estresse severo $\left(\mathrm{H}_{3}\right.$ :
$40 \% ; 1,08$ L). Os vasos, umidecidos de acordo com os respectivos tratamentos, constituíram as unidades experimentais formadas por uma única muda de cana-de-açúcar. O controle da disponibilidade hídrica foi realizado a cada dois dias, por meio da pesagem dos vasos, tendose utilizando balança digital com capacidade máxima de $25 \mathrm{~kg}$ e precisão de $\pm 0,005 \mathrm{~kg}$; a reposição da água evapotranspirada foi realizada sempre que a variação entre a massa inicial do vaso e a massa obtida no dia da avaliação fosse igual ou superior a $\%$ (MARIN, 2003).

Para o estabelecimento dos tratamentos de acidez foram utilizados, como referência, os valores da saturação por bases (V\%) presentes em Raij et al. (1997), a saber: baixa (30\% a $49 \%)$, média ( $50 \%$ a $74 \%)$ e alta $(75 \%$ a $100 \%)$. Considerando-se o índice de saturação por bases $(\mathrm{V} \%)$ da análise de solo inicial (Tabela 1) foram estabelecidos três tratamentos de acidez: $\mathrm{A}_{1}(0,0$ $\mathrm{mmol}_{\mathrm{c}} \mathrm{dm}^{-3}$ de $\mathrm{Al}^{+3} ; \mathrm{V}=55 \%$; sem estresse), $\mathrm{A}_{2}$ (3,0 $\mathrm{mmol}_{\mathrm{c}} \mathrm{dm}^{-3} \mathrm{de}^{+3} \mathrm{l}^{+3} ; \mathrm{V}=33 \%$; estresse moderado $)$ e $\mathrm{A}_{3}\left(6,0 \mathrm{mmol}_{\mathrm{c}} \mathrm{dm}^{-3} \mathrm{de} \mathrm{Al}^{+3} ; \mathrm{V}=23 \%\right.$; estresse severo), obtidos por meio da incubação do solo com calcário calcinado $(\mathrm{CaO}=59 \%$, $\mathrm{MgO}=9,7 \%, \mathrm{PN}=130 \%$ e $\mathrm{PRNT}=130 \%$ ), por 30 dias (Tabela 2).

Tabela 2. Análise química de Latossolo Vermelho distrófico álico, após 30 dias de incubação com calcário calcinado (PRNT 130\%).

\section{Análise Química}

\begin{tabular}{|c|c|c|c|c|c|c|c|c|c|c|c|c|}
\hline \multirow[t]{2}{*}{ Tratamentos } & \multirow[t]{2}{*}{$\mathrm{pH} \mathrm{CaCl}_{2}$} & \multirow{2}{*}{$\begin{array}{c}\text { M.O. } \\
\mathrm{g} \mathrm{dm}^{-3}\end{array}$} & \multirow{2}{*}{$\frac{P \text { resina }}{\mathrm{mg} \mathrm{dm}^{-3}}$} & $\mathbf{K}$ & Ca & Mg & Al & $\mathbf{H}+\mathbf{A l}$ & SB & $\mathbf{T}$ & $\mathbf{V}$ & $\mathbf{m}$ \\
\hline & & & & \multicolumn{7}{|c|}{$\mathrm{mmol}_{\mathrm{c}} \mathrm{dm}^{-3}$} & \multicolumn{2}{|c|}{$\%$} \\
\hline A1 & 5,1 & 14 & 4 & 1,4 & 14 & 11 & 0,0 & 22 & 26,4 & 48,4 & 55 & 0,0 \\
\hline A2 & 4,6 & 14 & 5 & 1,3 & 8 & 6 & 3,0 & 31 & 15,3 & 46,3 & 33 & 16,4 \\
\hline A3 & 4,2 & 14 & 4 & 1,4 & 6 & 4 & 6,0 & 38 & 11,4 & 49,4 & 23 & 34,5 \\
\hline Análise inicial & 4,1 & 14 & 4 & 1,4 & 3 & 2 & 8,0 & 42 & 6,4 & 48,4 & 13 & 55,6 \\
\hline
\end{tabular}

M.O.: Matéria Orgânica; SB: Soma de Bases; T: Capacidade de Troca de Cátions; V: Saturação por Bases; m: Saturação de Alumínio. 
Aos 60 dias sob efeito da interação dos estresses hídrico e ácido no solo, as plantas de cana-de-açúcar foram cortadas na altura do colo e o conteúdo de cada vaso foi colocado sobre peneira de $16 \mathrm{~mm}$ para separar o sistema radicular do solo, por meio de lavagem em água corrente. A seguir, as raízes foram cuidadosamente separadas em alíquotas de $1 \mathrm{~g}$ e acondicionadas em envelopes de papel alumínio para imediata determinação da atividade da enzima redutase do nitrato por método in vivo. Os teores de prolina livre foram determinados em alíquotas de $0,5 \mathrm{~g}$ de raízes acondicionadas em envelopes de papel alumínio e armazenadas sob temperatura de $80^{\circ} \mathrm{C}$ negativos. O restante das raízes foi separado, acondicionado em frascos contendo solução de álcool a 20\% (v/v) e conservado sob refrigeração. Posteriormente, foi colocado em sacos de papel e levado para secar em estufa de circulação forçada de ar em temperatura de $80^{\circ} \mathrm{C}$ até a obtenção da massa constante. Para determinação da massa seca $(\mathrm{g})$, foi utilizada uma balança analítica Denver Instrument Company AA-200.
A atividade da enzima redutase do nitrato foi determinada de acordo com o método in vivo de Jaworski (1971) e adaptado por Cazetta (1997). A atividade da enzima foi expressa em $\mu g g^{-1} h^{-1}$ $\mathrm{N}-\mathrm{NO}^{2}$ de massa fresca de raízes.

Os teores de prolina livre foram determinados pelo método de Bates; Waldren; Teare (1973), e calculados com base na massa fresca, segundo a fórmula:

$\left[\left(\mu \mathrm{g}\right.\right.$ prolina $/ \mathrm{mL}_{\mathrm{x}} \mathrm{mL}$ tolueno $) / 115,5 \mu \mathrm{g} /$ $\mu \mathrm{mol}] /[(\mathrm{g}$ amostra $) / 5]=\mu \mathrm{mol}$ de prolina $/ \mathrm{g}$ massa fresca de raízes.

\section{Resultados e Discussão}

As análises de variância para a atividade da enzima redutase do nitrato, teores de prolina livre, densidade e massa seca de raízes de canade-açúcar, sob efeito da disponibilidade hídrica e da acidez do solo estão apresentadas na Tabela 3.

Tabela 3. Análises de variância da atividade da enzima redutase do nitrato, dos teores de prolina livre, da densidade e da massa seca de raízes de plantas jovens de cana-de-açúcar, cv. IAC91-5155, sob efeito associado da disponibilidade hídrica e da acidez do solo, aos 60 dias.

\begin{tabular}{|c|c|c|c|c|c|}
\hline \multirow{3}{*}{$\begin{array}{l}\text { Causa } \\
\text { Da } \\
\text { Variação }\end{array}$} & \multirow[t]{3}{*}{ G.L. } & \multicolumn{3}{|c|}{ Quadrados Médios } & \multirow{3}{*}{$\begin{array}{c}\text { Massa seca } \\
\text { (g) }\end{array}$} \\
\hline & & $\mathbf{R N}^{1}$ & $\mathrm{PRO}^{2}$ & Densidade & \\
\hline & & $\mu \mathrm{gN}-\mathrm{NO}^{2} \mathrm{~g}^{-1} \mathrm{~h}^{-1}$ & $\mu \mathrm{mol} \mathrm{g}^{-1} \mathrm{MF}$ & $\left(\mathbf{m m ~ d m} \mathbf{m}^{-3}\right)$ & \\
\hline Disponibilidade hídrica $(\mathrm{H})$ & 2 & $0,0103^{\text {ns }}$ & $0,0143^{\text {ns }}$ & $1702,8087^{* *}$ & $40,0992 * *$ \\
\hline Acidez (A) & 2 & $0,0347^{* *}$ & $0,2797 * *$ & $55,7210^{*}$ & $0,3908^{\text {ns }}$ \\
\hline Interação HxA & 4 & $0,0146^{*}$ & $0,1621 * *$ & $23,4839^{\text {ns }}$ & $0,6923^{\mathrm{ns}}$ \\
\hline Tratamentos & 8 & 0,0185 & 0,1545 & 451,3744 & 10,4686 \\
\hline Blocos & 3 & $0,0242 * *$ & $0,0096^{\mathrm{ns}}$ & $12,9393^{\mathrm{ns}}$ & $0,1305^{\mathrm{ns}}$ \\
\hline Resíduo & 24 & 0,0043 & 0,0058 & 15,5261 & 0,6642 \\
\hline CV $(\%)$ & & 21,8005 & 10,6710 & 19,7374 & 23,3900 \\
\hline
\end{tabular}


Houve aumento significativo da atividade da enzima redutase do nitrato nas raízes de canade-açúcar com a redução da disponibilidade hídrica $\left(\mathrm{H}_{1}=70 \%\right.$ para $\left.\mathrm{H}_{2}=55 \%\right)$ associada à acidez moderada do solo $\left(\mathrm{A}_{2}=33 \%\right)$ e com o aumento da acidez do solo $\left(\mathrm{A}_{1}=55 \%\right.$ para $\mathrm{A}_{2}=33 \%$ ) associada às condições moderadas de disponibilidade hídrica $\left(\mathrm{H}_{2}=55 \%\right)$, Figuras 1 e 2 , respectivamente. A tolerância dos vegetais à redução da disponibilidade hídrica envolve mecanismos complexos, dependentes da ação e da interação de características morfológicas, fisiológicas e bioquímicas, como o aumento da atividade da enzima redutase do nitrato (MITRA, 2001). Esta enzima citosólica tem a síntese e a atividade induzidas pelo nitrato, $\mathrm{NO}_{3}^{-}$(DONATO et al., 2004). Tal fato pode explicar o aumento da atividade enzimática até os valores de moderada disponibilidade hídrica e acidez no solo, provavelmente, devido à presença constante do nitrato no meio de incubação, que permite a síntese de novo da enzima (ANDRADE NETTO,
2005).

Contudo, a partir de 53,17\% de disponibilidade hídrica associada à acidez moderada do solo $\left(\mathrm{A}_{2}=33 \%\right)$ e $39,42 \%$ de saturação por bases associada às condições hídricas moderadas no solo $\left(\mathrm{H}_{2}=55 \%\right)$, houve drástica redução da atividade da enzima redutase do nitrato conforme o aumento da intensidade da deficiência hídrica (Figura 1) e da acidez no solo (Figura 2). Neste caso, a redução da atividade da enzima pode ser explicada em função do decréscimo no fluxo de $\mathrm{NO}_{3}^{-}$, principal íon regulador da síntese da enzima redutase do nitrato, por falta de umidade no solo (ANDRADE NETTO, 2005). Em cana-de-açúcar sob deficiência hídrica e acidez moderada do solo também se constatou redução da atividade desta enzima (NAIK et al., 2002), corroborando com os resultados do presente trabalho. Em raízes de plântulas de arroz (SHARMA; DUBEY, 2005) e em Arabidopsis (XU; ZHOU, 2004) houve diminuição da atividade da enzima redutase do nitrato com o aumento da severidade da deficiência hídrica no solo.

Figura 1. Atividade da enzima redutase do nitrato em raízes de plantas jovens de cana-de-açúcar, cv. IAC91-5155, sob efeito associado da disponibilidade hídrica e da acidez moderada do solo, aos 60 dias.

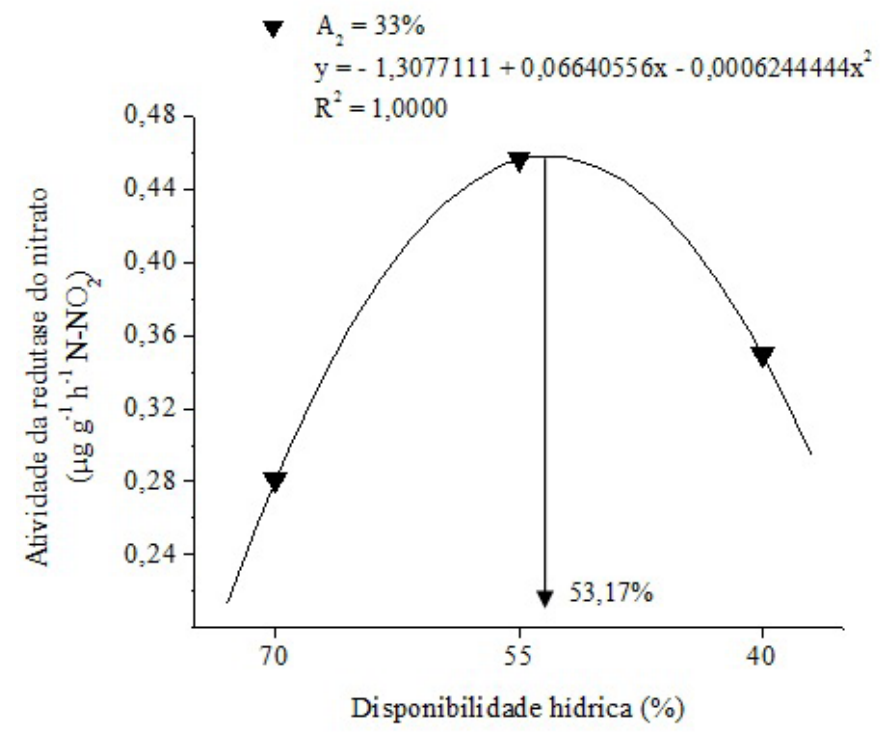


Figura 2. Atividade da enzima redutase do nitrato em raízes de plantas jovens de cana-de-açúcar, cv. IAC91-5155, sob efeito associado da disponibilidade hídrica moderada e da acidez do solo, aos 60 dias.

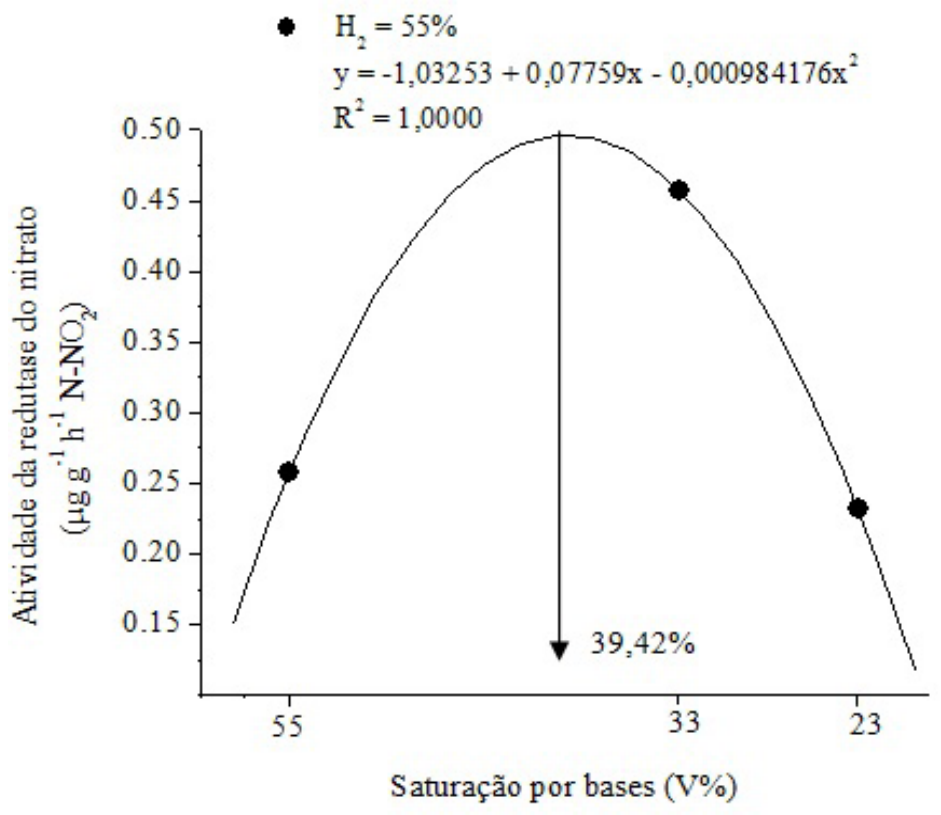

De modo geral, o metabolismo do nitrogênio é influenciado negativamente pela deficiência hídrica (FERREIRA et al., 2002) e pela acidez do solo (SHARMA; DUBEY, 2005). Em solos ácidos, o amônio $\left(\mathrm{NH}_{4}^{+}\right)$, principal fonte de nitrogênio, fica adsorvido às partículas coloidais, enquanto $\mathrm{O} \mathrm{NO}_{3}^{-}$, por ter carga negativa, tornase componente da solução do solo, facilmente lixiviado, e indisponível para a absorção radicular (CORDEIRO, 2004). Considerando este aspecto, se houver deficiência hídrica associada à acidez do solo, a absorção e o transporte de $\mathrm{NO}_{3}^{-}$pelas raízes diminui significativamente. A redução da disponibilidade do íon nitrato para as plantas pode inibir a transcrição do gene da enzima redutase do nitrato, bem como a estabilidade dos mRNAs desta enzima (SHARMA; DUBEY, 2005).

Os teores de prolina livre aumentaram linearmente conforme a redução da disponibilidade hídrica $\left(\mathrm{H}_{1}=70 \%\right.$ para $\left.\mathrm{H}_{3}=40 \%\right)$ e da baixa acidez do solo $\left(\mathrm{A}_{1}=55 \%\right)$, evidenciando que a prolina atuou como osmoprotetor para a manutenção hídrica das células radiculares (Figura 3). Na função de osmólito compatível, a prolina livre se acumula para preservar o metabolismo celular sob condições adversas, constituindo-se o aminoácido mais pesquisado nas respostas dos vegetais superiores aos estresses abióticos (GIANNAKOULA et al., 2008). Ainda, a prolina atua na proteção de macromoléculas, promovendo a retenção de água in situ (KAVI KISHOR et al., 2005). As condições de deficiência hídrica no solo causaram acúmulo de prolina livre na cv. IAC91-5155 de cana-de-açúcar (QUEIROZ et al., 2008), corroborando com os resultados do presente trabalho. Em plantas sob estresse hídrico, é sintetizada também nos tecidos foliares, translocada pelo floema até as raízes, onde se acumula para preservar e manter o turgor das células radiculares (RAYMOND; SMIRNOFF, 2002). 
Figura 3. Teores de prolina livre em raízes de plantas jovens de cana-de-açúcar, cv. IAC91-5155, sob efeito da disponibilidade hídrica e da baixa acidez do solo, aos 60 dias.

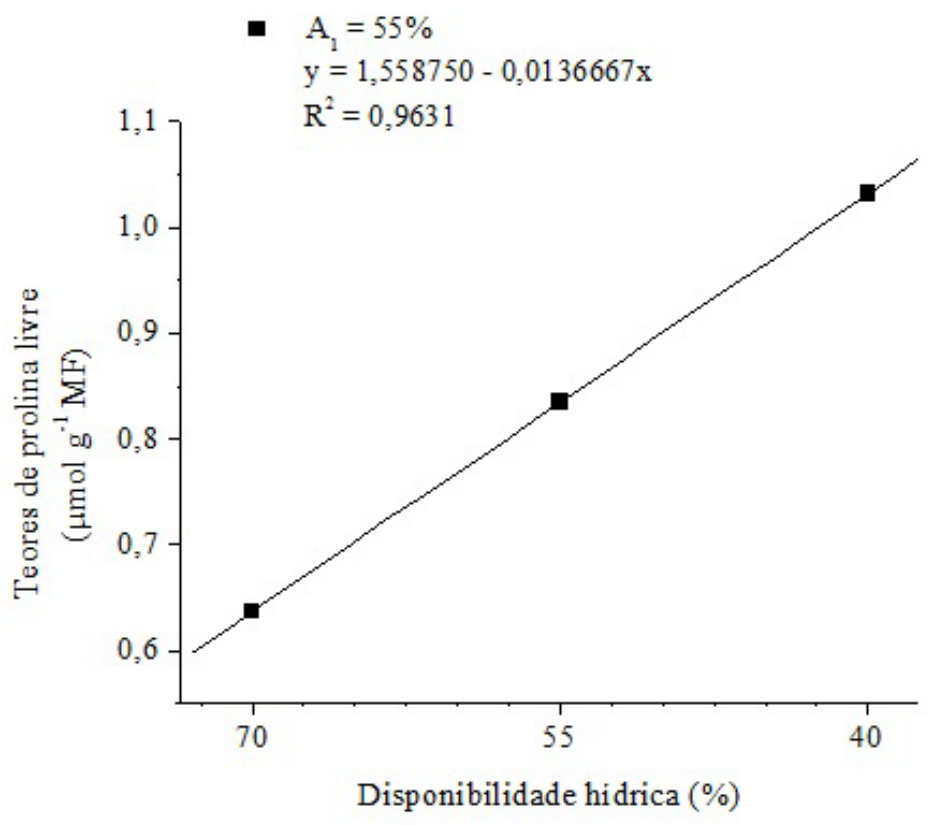

Os tratamentos de estresse hídrico associados à acidez moderada do solo $\left(\mathrm{A}_{2}=33 \%\right)$ causaram aumento dos teores de prolina livre até $56,18 \%$ de disponibilidade hídrica, a partir do qual houve drástica redução deste aminoácido (Figura 4), mostrando que sob condições de moderada disponibilidade hídrica e severa acidez do solo $\left(\mathrm{A}_{3}=23 \%\right)$ não ocorre acúmulo de prolina livre. Também, ocorreu redução dos teores deste aminoácido sob condições de severa acidez $\left(\mathrm{A}_{3}=\right.$ $23 \%$ ) associada aos tratamentos de 70 a $52,40 \%$ de disponibilidade hídrica no solo (Figura 5).

Estes resultados sugerem que as raízes da cana-de-açúcar, cv. IAC91-5155 apresentaram aumento dos teores de prolina livre sob a associação dos estresses hídrico e ácido em condições severas, revelando o efeito osmoprotetor deste aminoácido (Figura 5). O acúmulo de prolina livre em plantas jovens de guandu, arroz e cana-de-açúcar sob condições severas de disponibilidade hídrica e acidez do solo foi causado pelo efeito sinergístico de ambos os estresses (MARIN, 2003; SHARMA; DUBEY, 2005; CARLIN; SANTOS, 2009). Neste caso, o acúmulo de prolina livre pode ter sido ocasionado pelo decréscimo na degradação ou pelo aumento da biossíntese desse aminoácido (HARE; CRESS; STANDEN, 1999). A biossíntese de prolina pode ser induzida pelo aumento de poliaminas, arginina, ornitina, e, desta maneira, alterar o metabolismo de aminoácidos sob estresse (SILVEIRA; ROCHA; VIÉGAS, 2002).

Para a disponibilidade hídrica nos tratamentos de acidez do solo verifica-se que, conforme ocorreu aumento da acidez houve diminuição dos teores de prolina livre até $42,59 \%$ e $36,47 \%$ de saturação por bases (Figuras 6A e 6B). A partir desses índices associados à disponibilidade hídrica do solo $\left(\mathrm{H}_{1}=70 \%\right.$ e $\left.\mathrm{H}_{3}=40 \%\right)$, ocorreu acentuado acúmulo de prolina livre. A interação severa dos estresses evidenciou efeito osmoprotetor da prolina livre conduzindo ao ajustamento osmótico do vegetal. 
Figura 4. Teores de prolina livre em raízes de plantas jovens de cana-de-açúcar, cv. IAC91-5155, sob efeito associado da disponibilidade hídrica e da moderada acidez do solo, aos 60 dias.

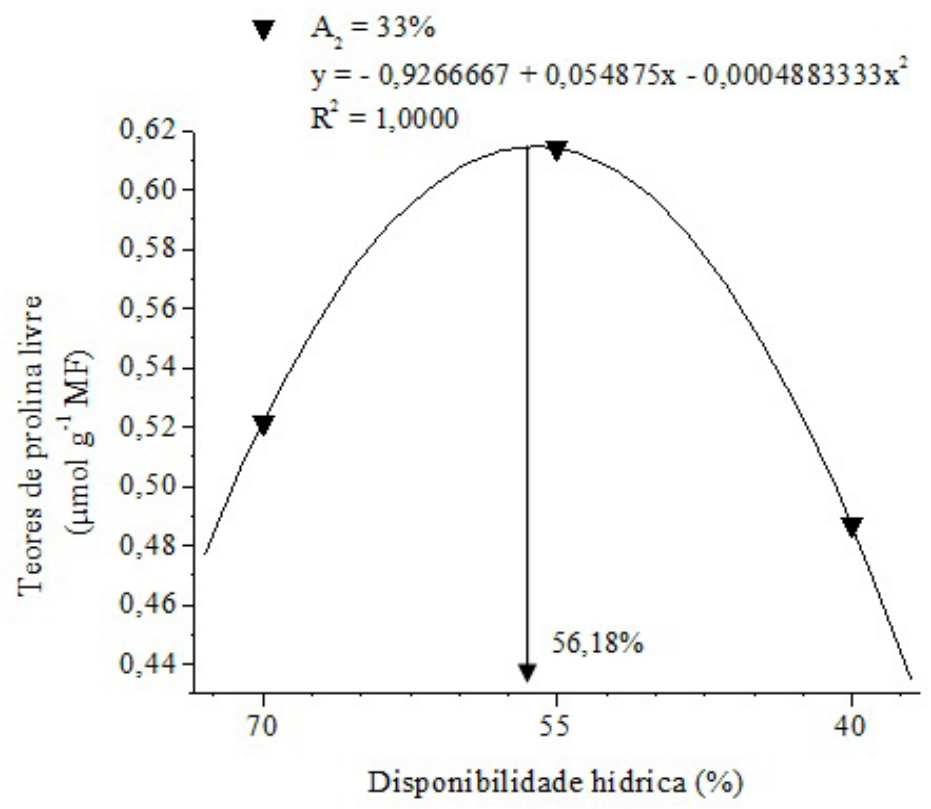

Figura 5. Teores de prolina livre em raízes de plantas jovens de cana-de-açúcar, cv. IAC91-5155, sob efeito associado da disponibilidade hídrica e da severa acidez do solo, aos 60 dias.

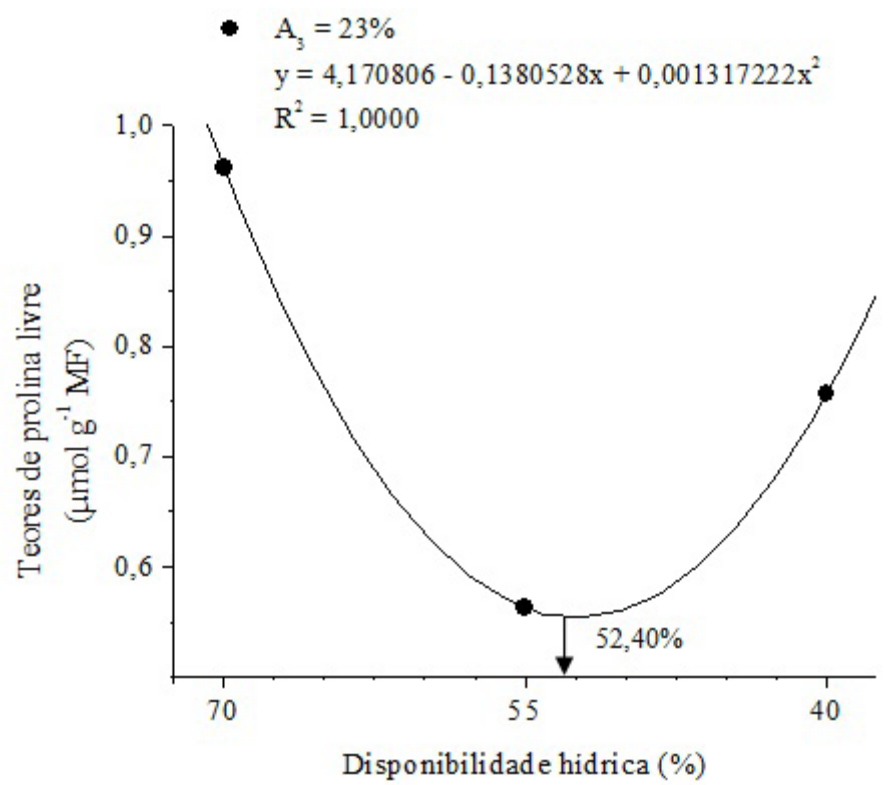


Figura 6. Teores de prolina livre em raízes de plantas jovens de cana-de-açúcar, cv. IAC91-5155, sob efeito associado da disponibilidade hídrica e da acidez do solo, aos 60 dias. A. Disponibilidade hídrica $\left(\mathrm{H}_{1}=70 \%\right)$ dentro dos tratamentos de acidez do solo $(\mathrm{V} \%)$. B. Disponibilidade hídrica $\left(\mathrm{H}_{3}=40 \%\right)$ dentro dos tratamentos de acidez do solo (V\%).
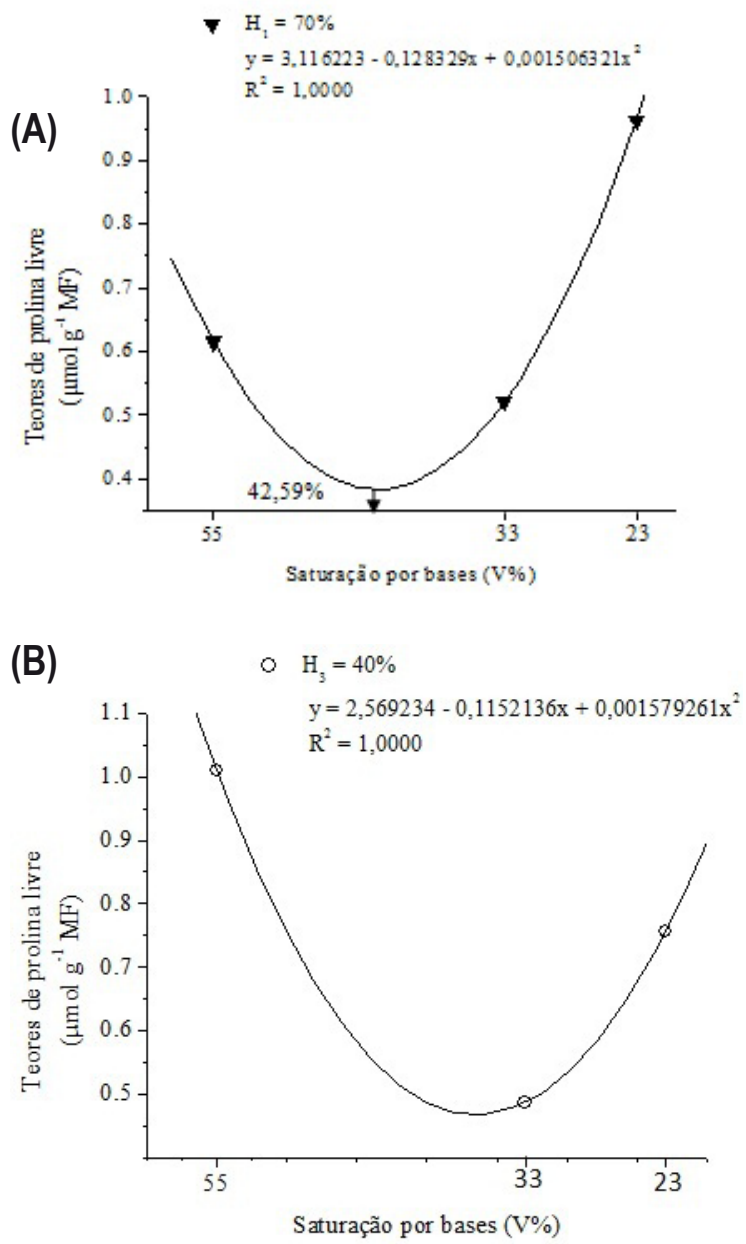

No sistema radicular de sorgo e milho sob efeito associado dos estresses hídrico e ácido, verificou-se aumento nos teores de prolina livre (ZAIFNEJAD; CLARK; SULLIVAN, 1997). Em plântulas de grão de bico cultivadas sob elevada concentração de alumínio houve aumento dos teores de prolina livre (SATAKOPAN; BASKARAN; SANKAR, 1992). Os mecanismos fisiológicos envolvidos em resposta à deficiência hídrica devem ser similares àqueles em resposta ao estresse ácido (ZAIFNEJAD; CLARK; SULLIVAN, 1997).

O crescimento das raízes de cana-de- açúcar foi drasticamente reduzido pelos estresses estudados (Tabela 3, Figuras 7 a 9). O aumento da restrição hídrica no solo provocou redução da densidade e da massa seca das raízes (Figuras 7 e 8). A deficiência hídrica é considerada fator limitante para a produtividade agrícola, porque reduz a expansão celular e o crescimento vegetal (TAIZ; ZEIGER, 2009). No período máximo de desenvolvimento da cana-de-açúcar, a deficiência hídrica provoca redução significativa na produtividade, visto que a cultura necessita de 250 partes de água para formar uma parte de massa seca da planta (ROSENFELD; LEME, 1984). 
Figura 7. Densidade de raízes de plantas jovens de cana-de-açúcar, cv. IAC91-5155 sob efeito da disponibilidade hídrica, aos 60 dias.

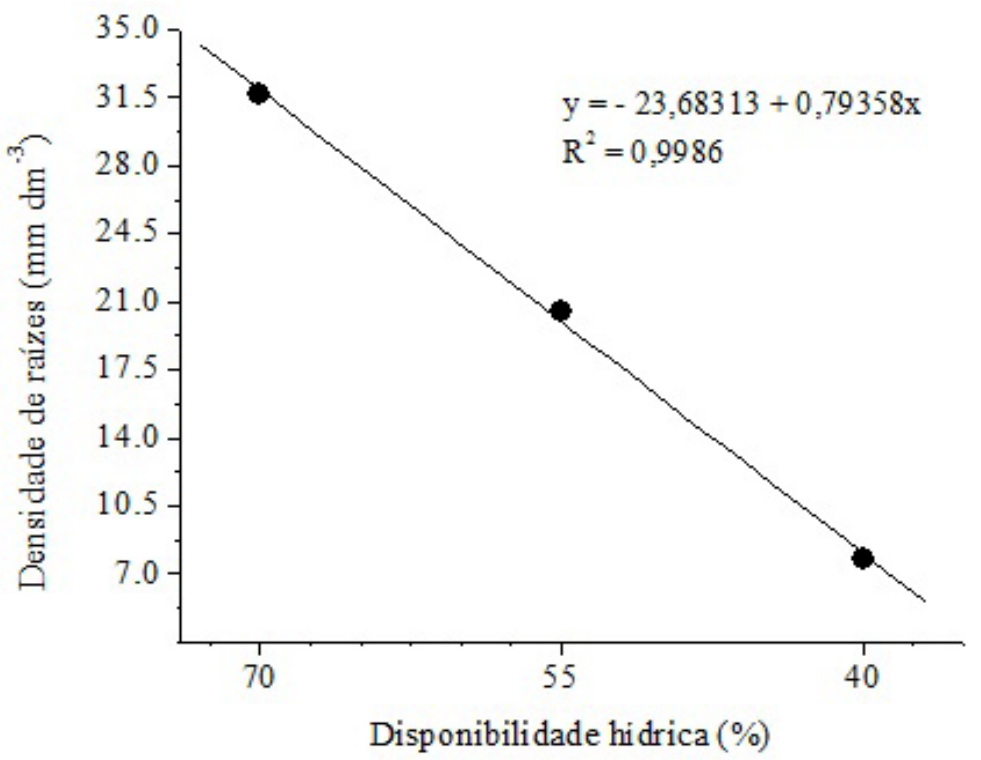

Figura 8. Massa seca de raízes de plantas jovens de cana-de-açúcar, cv. IAC91-5155 sob efeito da disponibilidade hídrica, aos 60 dias.

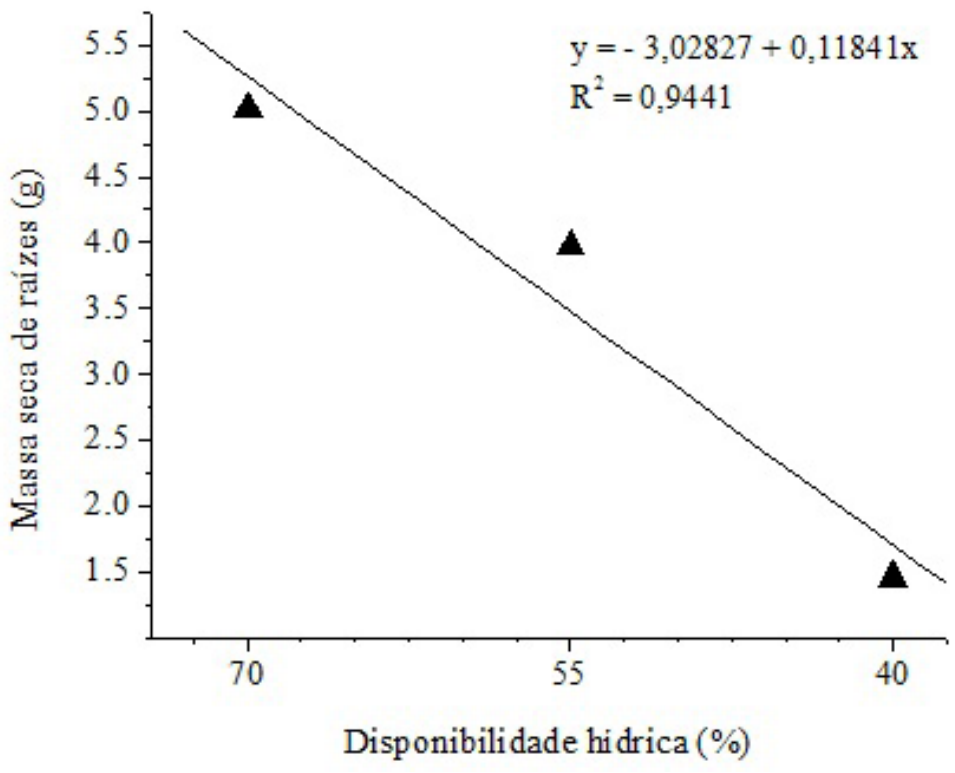

Em cana-de-açúcar sob deficiência à deficiência hídrica, houve significativa hídrica, por 120 dias, houve significativa redução da massa seca, conduzindo a redução da massa seca e da densidade diminuição do crescimento da cultura das raízes, conforme a diminuição da em 46,3\% e 60,8\%, sob condições de disponibilidade de água no solo (BIDOIA, estresse hídrico moderado e severo, 2005). Em diferentes estádios de respectivamente (RAMESH, 2000). crescimento da cana-de-açúcar submetida

As modificações fisiológicas do sistema 
radicular em plantas de cana-de-açúcar o sistema radicular da cv. IAC91sob estresse hídrico são influenciadas 5155 de cana-de-açúcar. Os resultados pelo estádio vegetativo da cultura, pela severidade e periodicidade da deficiência hídrica e, ainda, pelas características granulométricas do solo, que interferem no conteúdo de água disponível (QUEIROZ et al., 2008). Assim, a produtividade das plantas, limitada pela água, depende da quantidade disponível deste recurso e da eficiência de seu uso pelo vegetal (TAIZ; ZEIGER, 2009).

evidenciaram que a densidade de raízes foi reduzida significativamente, apresentando maior diminuição sob 35,11\% de saturação por bases (Figura 9). Muitas cultivares de cana-de-açúcar são adaptadas a solos ácidos e de baixa fertilidade (ROSSETTO et al., 2004), porém, a toxicidade por alumínio causa efeitos deletérios no crescimento das raízes, interferindo na absorção de água e nutrientes (SOBRAL; GUIMARÃES,

A acidez do solo também influenciou 1992).

Figura 9. Densidade de raízes de plantas jovens de cana-de-açúcar, cv. IAC91-5155 sob efeito da acidez do solo, aos 60 dias.

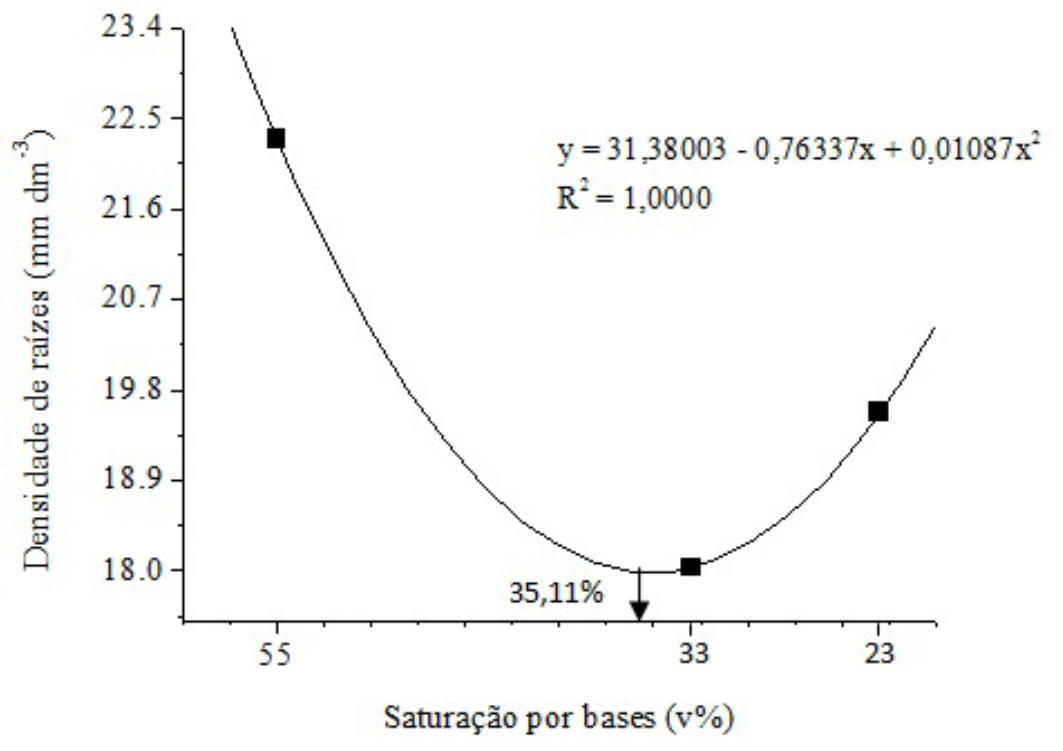

\section{Conclusão}

Nas raízes da cultivar IAC91-5155 de cana-de-açúcar, a atividade da enzima redutase do nitrato é indicadora fisiológica do efeito da associação do estresse hídrico e da acidez em condições moderadas no solo, enquanto, a prolina livre é indicadora desses estresses em condições severas. A intensificação da deficiência hídrica reduz o crescimento das raízes de cana-de-açúcar.

\section{Agradecimentos}

Ao Pesquisador Científico, Dr. Marcelo de Almeida Silva, da APTA Pólo CentroOeste, Jaú, SP, pelo fornecimento das mudas 
de cana-de-açúcar, cv. IAC91-5155 e pela contribuição na execução deste trabalho; aos docentes da Universidade Estadual Paulista, Faculdade de Ciências Agrárias e Veterinárias, Campus de Jaboticabal, Prof. Dr. José Frederico Centurion, pelo auxílio e desenvolvimento das análises de solo, e Prof. Dr. Jairo Osvaldo Cazetta, pela assistência e realização das análises da atividade da enzima redutase do nitrato.

\section{Referências}

ABDUL JALEEL, C.; MANIVANNAN, P.; KISHOREKUMAR, A.; SANKAR, B; GOPI, R.; SOMASUNDARAM, R.; PANEERSELVAM, R. Alterations in osmoregulations, antioxidant enzymes and indole alkaloid levels in Catharanthus roseus exposed to water deficit. Colloids and Surfaces B: Biointerfaces, Amsterdam, v. 59, n. 2, p. 150-157, 2007.

ANUÁRIO DA AGRICULTURA BRASILEIRA - AGRIANUAL. São Paulo: FNP Consultoria \& Comércio, 2008. 502 p.

ANDRADE NETTO, J. F. Atividade das enzimas redutase do nitrato e glutamina sintetase em cafeeiro arábica. 2005. Dissertação (Mestrado em Agronomia, Área de Concentração em Fitotecnia) - Escola Superior de Agricultura Luiz de Queiroz. Universidade de São Paulo, Piracicaba.

BANZATTO, D. A.; KRONKA, S. N. Experimentação agrícola. 4. ed. Jaboticabal: FUNEP, 2006. 237 p.

BATES, L. S.; WALDREN, R. P.; TEARE, I. D. Rapid determination of free proline for water stress studies. Plant and Soil, The Hague, v. 39, p. 205207, 1973.

BIDOIA, M. A. P. Desenvolvimento inicial e acúmulo de prolina livre em cultivares de cana-deaçúcar sob efeito da disponibilidade hídrica do solo. 2005. Dissertação (Mestrado em Agronomia. Área de Concentração em Produção Vegetal) - Faculdade de Ciências Agrárias e Veterinárias. Universidade Estadual Paulista, Jaboticabal.

CARLIN, S. D.; SANTOS, D. M. M. dos. Indicadores fisiológicos da interação entre déficit hídrico e acidez do solo em cana-de-açúcar. Pesquisa Agropecuária Brasileira, Brasília, v. 44, n. 9, p. 1106-1113, 2009.

CASARIN, V.; VILlA NOVA, V. S.; FORLI, F. Micronutrientes em cana-de-açúcar. In: MARQUES, M. O.; MUTTON, M. A.; AZANiA, A. A. P. M.; TASSO JUNIOR, L. C. NOGUEIRA, G. A.; VALE, D. W. (Ed.). Tópicos em tecnologia sucroalcooleira. Jaboticabal: Gráfica Multipress Ltda., 2006. p. 6576.

CAZETTA, J. O. Influência do nitrogênio e potássio no metabolismo, no desenvolvimento e na produção de plantas de milho. 1997. Tese (Livre Docência) - Faculdade de Ciências Agrárias e Veterinárias. Universidade Estadual Paulista, Jaboticabal.

CLAESSEN, M. E. C. (Org.). Manual de métodos de análise de solo. 2. ed. rev. atual. Rio de Janeiro: Embrapa-CNPS, 1997. 212 p. (EMBRAPA-CNPS. Documentos, 1).

CORDEIRO, L. Fixação do nitrogênio. In: KERBAUY, G. B. Fisiologia vegetal. Rio de Janeiro: Editora Guanabara Koogan, 2004. 452 p.

DONATO, V. M. T. S.; ANDRADE, A. G.; SOUZA, E. S.; FRANÇA, J. G. E.; MACIEL, G. A. Atividade enzimática em variedades de canade-açúcar cultivadas in vitro sob diferentes níveis de nitrogênio. Pesquisa Agropecuária Brasileira, Brasília, v. 39, n. 11, p. 1087-1093, 2004.

DRUMMOND, R. D.; GUIMARÃES, C. T.; FELIX, J.; NINAMANGO-CÁRDENAS, F. E.; CARNEIRO, N. P.; PAIVA, E.; MENOSSI, M. Prospecting sugarcane genes involved in aluminium tolerance. Genetics and Molecular Biology, Ribeirão Preto, v. 24, n. 1/4, p. 221-230, 2001.

FERREIRA, V. M.; MAGALHÃES, P. C.; DURÃES, F. O. M.; OLIVEIRAS, L. E. M.; PURCINO, A. A. C. Metabolismo do nitrogênio associado à deficiência hídrica e sua recuperação em genótipos de milho. Ciência Rural, Santa Maria, v. 32, n. 1, p. 13-17, 2002.

GIANNAKOULA, A.; MOUSTAKAS, M.; MYLONA, P.; PAPADAKIS, I.; YUPSANIS, T. Aluminum tolerance in maize is correlated with increased levels of mineral nutrients, carbohydrates and proline, and decreased levels of lipid peroxidation and Al accumulation. Journal of Plant Physiology, Stuttgart, v. 165, n. 4, p. 385-396, 2008.

GRENNAN, A. K. Abiotic stress in rice. An "Omic" approach. Plant Physiology, Illinois, v. 140, n. 4, p. 1139-1141, 2006.

HARE, P. D.; CRESS, W. A.; STANDEN, J. Van. Proline synthesis and degradation: a model system 
for elucidating stress-related signal transduction. Journal of Experimental Botany, Oxford, v. 50, n. 333, p. 413-434, 1999.

JAWORSKI, E. G. Nitrate reductase assay in intact plant tissues. Biochemical and Biophysical Research Communications, London, v. 43, n. 6, p. 1274-1279, 1971.

KAVI KISHOR, P. B.; SANGAM, S.; AMRUTHA, R. N.; SRI LAXMI, P.; NAIDU, K. R.; RAO, K. R. S. S.; RAO, S.; REDDY, K. J.; THERIAPPAN, P.; SREENIVASULU, N. Regulation of proline biosynthesis, degradation, uptake and transport in higher plants: Its implications in plant growth and abiotic stress tolerance. Current Science, Columbus, v. 88, n. 3, p. 424-438, 2005.

MARIN, A. Influência associada do estresse hídrico e do alumínio na germinação e crescimento inicial do guandu (Cajanus cajan (L.) Millsp.). 2003. Dissertação (Mestrado em Agronomia. Área de Concentração em Produção Vegetal) - Faculdade de Ciências Agrárias e Veterinárias. Universidade Estadual Paulista, Jaboticabal.

MITRA, J. Genetics and genetic improvement of drought resistance in crop plants. Current Science, Columbus, v. 80, n. 6, p.758-763, 2001.

NAIK, R. M.; KADAM, B. S.; PANDHARE, R. A.; PAWAR, S. M.; PATIL, R. C.; BHOI, P. G. Inheritance of proline accumulation and in vivo nitrate reductase activity in sugarcane leaves under water stress. Indian Sugar, New Delhi, v. 52, n. 6, p. 427-429, 2002.

OLIVEIRA, M. A. J.; BOVI, M. L. A.; MACHADO, E. C.; RODRIGUES, J. D. Atividade da redutase de nitrato em mudas de pupunheira (Bactris gasipaes). Ciência Rural, Santa Maria, v. 35, n. 3, p. 515-522, 2005.

QUEIROZ, R. J. B.; SANTOS, D. M. M.; CARLIN, S. D.; MARIN, A.; BANZATTO, D. A.; CAZETTA, J. O. Osmoprotetores em cana-de-açúcar sob efeito da disponibilidade hídrica no solo. Científica, Jaboticabal, v. 36, n. 2, p. 107-115, 2008.

RAIJ, B. van; CANTARELLA, H.; QUAGGIO, J. A.; FURLANI, A. M. C. Recomendações de adubação e calagem para o Estado de São Paulo. 2. ed. Instituto Agronômico/Fundação IAC, 1997. 285 p. (Boletim técnico, 100).

RAMESH, P. Effect of different levels of drought during the formative phase on growth parameters and its relationship with dry matter accumulation in sugarcane. Journal Agronomy \& Crop Science,
Berlin, v. 85, n. 2, p. 83-89, 2000.

RAYMOND, M. J.; SMIRNOFF, N. Proline metabolism and transport in maize seedlings at low water potential. Annals of Botany, Oxford, v. 89, n. 7, p. 813-823, 2002.

ROSENFELD, U.; LEME, R. J. A. Produtividade da cana-de-açúcar irrigada por aspersão- estudo de épocas de irrigação. In: CONGRESSO NACIONAL DA STAB, 3., 1984, São Paulo. Anais... São Paulo: STAB, 1984. p. 77-84.

ROSSETTO, R.; SPIRONELLO, A.; CANTARElla, H.; QUAGGIO, J. A. Calagem para cana-de-açúcar e sua interação com a adubação potássica. Bragantia, Campinas, v. 63, n. 1, p. 105 119, 2004.

SATAKOPAN, V. N.; BASKARAN, G.; SANKAR, M. Changes in the levels of RNA, proline, phenol and ascorbic acid in $\mathrm{Al}^{3+}$ toxicity in chickpea seedlings. Indian Journal of Plant Physiology, New Delhi, v. 35, n. 3, p. 272-274, 1992.

SHARMA, P.; DUBEY, R. S. Modulation of nitrate reductase activity in rice seedlings under aluminium toxicity and water stress: role of osmolytes as enzyme protectant. Journal of Plant Physiology, Stuttgart, v. 162, n. 8, p. 854-864, 2005.

SHULAEV, V.; CORTES, D.; MILlER, G.; MITTLER, R. Metabolomics for plant stress response. Physiologia Plantarum, Blacksburg, v. 132, n. 2, p. 199-208, 2008.

SILVA, M. A.; SILVA, J. A. G.; ENCISO, J.; SHARMA, V.; JIFON, J. Yield components as indicators of drought tolerance of sugarcane. Scientia Agrícola, Piracicaba, v. 65, n. 6, p. 620627, 2008.

SILVEIRA, J. A. G.; ROCHA, I. M. A.; VIÉGAS, R. A. Metabolic responses of cowpea and cashew plants exposed to salt and water stress: new aspects on proline accumulation. 2002. Disponível em: <sbbq.iq.usp.br/arquivos/regional/ 2002/cdresumo/ Palestras/016.pdf>. Acesso em: 24 abr. 2009.

SOBRAL, A. F.; GUIMARÃES, V. O. S. Relação entra a toxicidez do alumínio e a produção de canade-açúcar (Saccharum spp.). Pesquisa Agropecuária Brasileira, Brasília, v. 27, n. 2, p. 287-292, 1992.

TAIZ, L.; ZEIGER, E. Fisiologia vegetal. 4. ed. Porto Alegre: Artmed, 2009. 848 p.

$\mathrm{XU}, \mathrm{Z}$.; ZHOU, G. Research advance in nitrogen metabolism of plant and its environmental regulation. Journal Applied of Ecology, Beijing, v. 
15, n. 3, p. 511-516, 2004.

ZAIFNEJAD, M.; CLARK, R. B.; SULLIVAN, C. Y. Aluminum and water stress effects on growth and proline of sorghum. Journal of Plant Physiology, Munich, v. 150, n. 3, p. 338-344, 1997. 
